This is an author produced version of a paper published in Journal of Molecular Structure.

This paper has been peer-reviewed but may not include the final publisher proof-corrections or pagination.

Citation for the published paper:

Ingmar Persson, Wantana Klysubun, Daniel Lundberg. (2019) A K-edge P XANES study of phosphorus compounds in solution. Journal of Molecular Structure. Volume: 1179, Number: 5 March 2019, pp 608-611.

https://doi.org/10.1016/j.molstruc.2018.11.059.

Access to the published version may require journal subscription.

Published with permission from: Elsevier.

Standard set statement from the publisher:

(C) Elsevier, 2019 This manuscript version is made available under the CC-BY-NC-ND 4.0 license http://creativecommons.org/licenses/by-nc-nd/4.0/

Epsilon Open Archive http://epsilon.slu.se 
Molecular structure

Elsevier Editorial System(tm) for Journal of Manuscript Draft

Manuscript Number:

Title: A K-edge P XANES Study of Phosphorus Compounds in Solution

Article Type: Research Paper

Keywords: Phosphorus K-edge XANES, inorganic and organic phosphates, organophosphorus compounds

Corresponding Author: Professor Ingmar Persson, Ph.D.

Corresponding Author's Institution: Swedish University of Agricultural Sciences

First Author: Ingmar Persson, Ph.D.

Order of Authors: Ingmar Persson, Ph.D.; Wantana Klysubun, Ph.D.; Daniel Lundberg, Ph.D.

Research Data Related to this Submission

There are no linked research data sets for this submission. The following reason is given:

All experimental data are reported in the paper as figure and Table, and the data are available in electronic form upon request from the authors. 


\title{
A K-edge P XANES Study of Phosphorus Compounds in Solution
} Ingmar Persson, ${ }^{\mathrm{a}, *}$ Wantana Klysubun, ${ }^{\mathrm{b}}$ and Daniel Lundberg ${ }^{\mathrm{a}}$

${ }^{a}$ Department of Molecular Sciences, Swedish University of Agricultural Sciences, P.O.Box 7015, SE-750 07 Uppsala, Sweden; e-mail address of corresponding author: ingmar.persson@ slu.se

${ }^{\mathrm{b}}$ Synchrotron Light Research Institute, 111 Moo 6, University Ave., Muang, Nakhon Ratchasima, 30000, Thailand.

Keywords: Phosphorus K-edge XANES, inorganic and organic phosphates, organophosphorus compounds

\begin{abstract}
The K-edge X-ray absorption near-edge structure (XANES) spectra of 19 phosphorus-containing compounds have been measured in solution. The energy at maximum intensity of the primary phosphate peak, regardless of chemical species, is $2154.5 \pm 0.5 \mathrm{eV}$. A few of the compounds studied feature XANES spectra which are conceivably characteristic enough to be used as positive identifiers in solution, including $O, O$-diethyldithiophosphate, $\left(\mathrm{C}_{2} \mathrm{H}_{5} \mathrm{O}\right)_{2} \mathrm{PS}(\mathrm{SH})$, triphenylphosphine oxide, $\left(\mathrm{C}_{6} \mathrm{H}_{5}\right)_{3} \mathrm{PO}$, and triphenylphosphite $\left(\mathrm{C}_{6} \mathrm{H}_{5} \mathrm{O}\right)_{3} \mathrm{P}$. However, most spectra are near-identical or similar enough to another compound to prohibit any useful quantification analysis. The narrow range of absorption edge energy, and all phosphorus compounds studied have an absorption edge at higher energy than elemental phosphorus (red phosphorus). This shows that the electron density of phosphorus in these compounds is lower than in elemental phosphorus, and the conventional use of oxidation numbers cannot be used.
\end{abstract}

\section{Introduction}

Sulfur K-edge X-ray absorption near-edge structure (XANES) spectroscopy has been proven to be very sensitive to the oxidation state with a wide range of absorption edge energies between the oxidation states -II and +VI, spanning ca. $13 \mathrm{eV} \mathrm{[1,2].} \mathrm{In} \mathrm{general,} \mathrm{the} \mathrm{energy} \mathrm{and} \mathrm{intensity} \mathrm{of} \mathrm{the} \mathrm{absorption} \mathrm{edge} \mathrm{of}$ sulfur compounds increases with increasing oxidation state, and highly symmetric coordination around the sulfur atom, as in the case of the sulfate ion, $\mathrm{SO}_{4}{ }^{2-}$, further increases the intensity of the absorption edge significantly, a so-called white line; the term white line refers to an intense absorption in the nearedge region, dating back to the use of photographic film when these absorption peaks showed up as a heavily exposed line on the developed film [3]. Furthermore, several kinds of sulfur compounds have unique absorption-edge features making them possible to distinguish from other sulfur compounds. These properties of the X-ray absorption of sulfur compounds made it possible to develop a combined qualitative and quantitative method to accurately determine the relative amounts of sulfur compounds in unknown samples [1].

The objective with the present study was to perform a similar study on phosphorus-containing compounds in solution as only a limited number of such data have been reported, phosphorus oxides and triorganophosphinechalcogenides as pure compounds, primarily in the solid state with data collection in transmission data [4-7]. A vast amount of studies have been performed on solid phosphate minerals to establish the mineral speciation from the phosphorus K-edge XANES spectra using a library of spectra of pure minerals $[8,9]$. However, this is a challenging task as the absorption edge the position of phosphate compounds hardly varies at all between phosphate minerals, and also due to the fact that the absorption 
intensity is similar between different phosphate minerals. The same difficulty can be said to exist for natural samples studied in soil science and biology, as they also primarily are phosphates $[10,11]$.

\section{Experimental \\ Chemicals}

Adenosine triphosphate (ATP), $\mathrm{C}_{10} \mathrm{H}_{16} \mathrm{~N}_{5} \mathrm{O}_{3}-\mathrm{P}_{3} \mathrm{O}_{10}$ (Sigma-Aldrich), di- $n$-butylphosphate, (n$\left.\mathrm{C}_{4} \mathrm{H}_{9} \mathrm{O}\right)_{2} \mathrm{PO}(\mathrm{OH})$ (Sigma-Aldrich), O,O-diethyldithiophosphate $\left(\mathrm{C}_{2} \mathrm{H}_{5} \mathrm{O}\right)_{2} \mathrm{PS}(\mathrm{SH})$ (Sigma-Aldrich), diphenylphosphate, $\left(\mathrm{C}_{6} \mathrm{H}_{5} \mathrm{O}\right)_{2} \mathrm{PO}(\mathrm{OH})$ (Sigma-Aldrich), ethylphosphonic acid, $\mathrm{C}_{2} \mathrm{H}_{5} \mathrm{PO}(\mathrm{OH})_{2}$ (SigmaAldrich), $\mathrm{N}$-(phosphonomethyl)glycine (a.k.a. glyphosate), $(\mathrm{OH})_{2} \mathrm{P}(\mathrm{O}) \mathrm{CH}_{2} \mathrm{NHCH}_{2} \mathrm{COOH}$ (SigmaAldrich), phosphoric acid, $\mathrm{H}_{3} \mathrm{PO}_{4}$ (Merck, $97 \%$ ), sodium dihydrogenphosphate monohydrate, $\mathrm{NaH}_{2} \mathrm{PO}_{4}$. $\mathrm{H}_{2} \mathrm{O}$ (Merck), sodium hydrogenphosphate heptahydrate, $\mathrm{Na}_{2} \mathrm{HPO}_{4} \cdot 7 \mathrm{H}_{2} \mathrm{O}$ (Merck), sodium phosphate dodecahydrate, $\mathrm{Na}_{3} \mathrm{PO}_{4} \cdot 12 \mathrm{H}_{2} \mathrm{O}$ (Merck), tetra- $n$-butylphosphonium bromide, $\left(n-\mathrm{C}_{4} \mathrm{H}_{9}\right)_{4} \mathrm{PBr}$ (SigmaAldrich), tri- $n$-butylphosphine oxide, $\left(n-\mathrm{C}_{4} \mathrm{H}_{9}\right)_{3} \mathrm{PO}$ (Sigma-Aldrich), triethylphosphate, $\left(\mathrm{C}_{2} \mathrm{H}_{5} \mathrm{O}\right)_{3} \mathrm{PO}$ (Sigma-Aldrich), triethylphosphite, $\left(\mathrm{C}_{2} \mathrm{H}_{5} \mathrm{O}\right)_{3} \mathrm{P}$ (Sigma-Aldrich), triphenylphosphate, $\left(\mathrm{C}_{6} \mathrm{H}_{5} \mathrm{O}\right)_{3} \mathrm{PO}$ (Sigma-Aldrich), triphenylphosphine oxide, $\left(\mathrm{C}_{6} \mathrm{H}_{5}\right)_{3} \mathrm{PO}$ (Sigma-Aldrich), triphenylphosphite, $\left(\mathrm{C}_{6} \mathrm{H}_{5} \mathrm{O}\right)_{3} \mathrm{P}$ (Sigma-Aldrich), tricyclohexylphosphine, $\left(\mathrm{C}_{6} \mathrm{H}_{11}\right)_{3} \mathrm{P}$ (Sigma-Aldrich), triphenylphosphine, $\left(\mathrm{C}_{6} \mathrm{H}_{5}\right)_{3} \mathrm{P}$ (Sigma-Aldrich) were used as purchased. Millipore filtered water was used for the preparation of aqueous solutions, and acetonitrile, $\mathrm{CH}_{3} \mathrm{CN}$ (Sigma-Aldrich, analytical grade), for the acetonitrile solutions. For each solution, weighed amounts of the respective phosphorus compound were dissolved in water or acetonitrile to $0.10 \mathrm{~mol} \cdot \mathrm{dm}^{-3}$ concentration.

\section{X-ray absorption data collection}

The X-ray absorption data were collected at the Synchrotron Light Research Institute (SLRI), Nakhon Ratchasima, Thailand, using the bending magnet beamline 8 [12]. SLRI operated at $1.2 \mathrm{GeV}$ and a ring current of 80-150 mA. The radiation was monochromatized by an InSb[111] double crystal monochromator, $d_{111}=3.7405 \AA$ [13]. The data were collected in fluorescence mode using a 13-element Ge array detector (Canberra, Ultra LegE Detector (GUL)). For each sample three scans were collected and averaged. The spectrum of red phosphorus, $\mathrm{P}_{n}$, was collected after each beam fill and thereafter at regular intervals assigning the first inflection point of the K-edge to $2145.5 \mathrm{eV} \mathrm{[14]} \mathrm{as} \mathrm{an} \mathrm{external} \mathrm{standard.} \mathrm{The}$ solutions were contained sample holders made of poly(methyl methacrylate) with one side made of $5 \mu \mathrm{m}$ polypropylene X-ray film (Nitto Denko Co., Japan).

\section{Results and discussion}

The P K-edge XANES spectra of all phosphorus compounds studied except the calibration reference (red phosphorus) and the organophosphines display a strong white line. The XANES spectra of phosphate compounds (inorganic phosphates, and mono-, di- and trialkyl- or triarylphosphates) have very similar XANES spectra with a strong white line at about $2154.5 \mathrm{eV}$, and a weaker, broader peak at ca. $2170 \mathrm{eV}$, Figure $1 \mathrm{a} \& 1 \mathrm{~b}$ and Table 1 . One exception is $O, O$-diethyldithiophosphate with its white line at 2152.2 $\mathrm{eV}$. This is due to that sulfur is less electron-withdrawing than oxygen thus causing a higher electron density on phosphorus and thus a lower excitation energy, Figure $1 \mathrm{~b}$. This strong absorption is due to the dipole-allowed transition $1 \mathrm{~s} \rightarrow 3 \mathrm{p}$, where the $3 \mathrm{p}$ orbital is empty for phosphate compounds with phosphorus in the oxidation state $+\mathrm{V}[6]$. The white line intensity of the inorganic phosphates, and mono-, di- and trialkyl- and triarylphosphates in $0.10 \mathrm{~mol} \cdot \mathrm{dm}^{-3}$ solution do not seem to follow any recognizable trend. However, it should be stressed that the intensity of data collected in fluorescence mode are sensitive to total absorption due to self-absorption, which is one of the reasons to collect data in reasonably dilute solutions. These results clearly show that it is very difficult, or even impossible, to qualitatively distinguish phosphate compounds in solution from one another with P K-edge XANES spectroscopy. 
Table 1. Energy of absorption maxima of phosphorus K-edge XANES spectra of phosphorus compounds in $0.10 \mathrm{~mol} \cdot \mathrm{dm}^{-3}$ aqueous or acetonitrile solution after normalization of the absorbance to 1.00 at $2200 \mathrm{eV}$. The spectra are collected in fluorescence mode. Maximum intensity of the peaks are given within parenthesis after the absorption maximum value for identification of the most intense peak; $s h=$ shoulder. Values in italics are those previously reported and the energy shift from our values are given in curly brackets.

XANES region peaks

Structure-related peaks

$\begin{array}{ll}\text { Phosphate compounds and ions } \\ \mathrm{H}_{3} \mathrm{PO}_{4}(\mathrm{aq}), \mathrm{pH}=1.0 & 2154.7(4.8) \\ \mathrm{H}_{2} \mathrm{PO}_{4}{ }^{-}(\mathrm{aq}), \mathrm{pH}=4.7 & 2154.9(5.7) \\ \mathrm{HPO}_{4}{ }^{2-}(\mathrm{aq}), \mathrm{pH}=9.8 & 2154.5(6.8) \\ \mathrm{PO}_{4}{ }^{-}(\mathrm{aq}), \mathrm{pH}=13.0 & 2154.6(4.8) \\ \mathrm{ATP}^{\mathrm{a}}(\mathrm{aq}) & 2154.7(5.3) \\ \left(\mathrm{n}-\mathrm{C}_{2} \mathrm{H}_{5} \mathrm{O}\right)_{2} \mathrm{PS}(\mathrm{SH})(\mathrm{an}) & 2152.2(4.4) \\ \left(\mathrm{n}^{-} \mathrm{C}_{4} \mathrm{H}_{9} \mathrm{O}\right)_{2} \mathrm{PO}(\mathrm{OH})(\mathrm{an}) & 2154.4(5.8) \\ \left(\mathrm{C}_{6} \mathrm{H}_{5} \mathrm{O}\right)_{2} \mathrm{PO}(\mathrm{OH})(\mathrm{an}) & 2154.8(5.0) \\ \left(\mathrm{C}_{2} \mathrm{H}_{5} \mathrm{O}\right)_{3} \mathrm{PO}(\mathrm{an}) & 2154.2(6.0) \\ \left(\mathrm{C}_{6} \mathrm{H}_{5} \mathrm{O}\right)_{3} \mathrm{PO}(\mathrm{an}) & 2154.4(6.1) \\ \left(\mathrm{C}_{6} \mathrm{H}_{5} \mathrm{O}\right)_{3} \mathrm{PO}(\mathrm{s}) & 2152.1\{-2.3\}\end{array}$

$2170.1(1.8)$

$2170.9(1.7)$

2169.8 (1.9)

2169.8 (1.7)

$2172.8(1.7)$

2161.4 (1.7)

$2168.5(2.0)$

2170.3 (1.7)

2168.9 (2.0)

2169.5 (2.0)

\section{Phosphites and phosphonates}

\begin{tabular}{|c|c|c|c|}
\hline$\left(\mathrm{C}_{6} \mathrm{H}_{5} \mathrm{O}\right)_{3} \mathrm{P}(\mathrm{an})$ & $2150.5(4.0)$ & & $2166.5(1.6)$ \\
\hline & $2153.6(2.5)$ & & \\
\hline$\left(\mathrm{C}_{6} \mathrm{H}_{5} \mathrm{O}\right)_{3} \mathrm{P}(\mathrm{s})^{\mathrm{a}, \mathrm{b}}$ & $2148.0\{-2.5\}$ & & \\
\hline & $2149.7\{-3.9\}$ & & \\
\hline$\left(\mathrm{C}_{2} \mathrm{H}_{5} \mathrm{O}\right)_{3} \mathrm{P}(\mathrm{an})$ & 2149.4 (1.9) & $2160.8(2.0)$ & $2168.0(1.6)$ \\
\hline & $2152.0(4.5)$ & & \\
\hline $\mathrm{C}_{2} \mathrm{H}_{5} \mathrm{PO}(\mathrm{OH})_{2}$ (an) & $2153.5(4.4)$ & & $2168.2(1.7)$ \\
\hline glyphosate (aq) & $2153.7(3.8)$ & $2159.6 \mathrm{sh}(1.28)$ & $2168.9(1.5)$ \\
\hline
\end{tabular}

$\begin{array}{ll}\text { Phosphine oxides } & \\ \left(\mathrm{C}_{4} \mathrm{H}_{9}\right)_{3} \mathrm{PO}(\mathrm{an}) & 2151.1(4.3) \\ \left(\mathrm{C}_{2} \mathrm{H}_{5}\right)_{3} \mathrm{PO}(\mathrm{l}){ }^{\mathrm{a}} & 2148.8\{-2.5\} \\ \left(\mathrm{C}_{6} \mathrm{H}_{5}\right)_{3} \mathrm{PO}(\mathrm{an}) & 2149.3(1.9) \\ & 2152.0(4.5) \\ \left(\mathrm{C}_{6} \mathrm{H}_{5}\right)_{3} \mathrm{PO} \text { (an) } & 2147.3\{-2.0\} \\ & 2150.0\{-2.0\}\end{array}$

$2164.1(1.7)$

$2160.5(2.0)$

2168.3 (1.6)

Organophosphines and the phosphonium ion

$\begin{array}{lll}\left(\mathrm{C}_{6} \mathrm{H}_{11}\right)_{3} \mathrm{P}(\mathrm{an}) & 2148.5(1.3) & 2165.5(1.3) \\ & 2151.3(2.4) & \\ & 2155.4(1.6) & \\ \left(\mathrm{C}_{2} \mathrm{H}_{5}\right)_{3} \mathrm{P}(\mathrm{l}){ }^{\text {a }} & 2145.8\{-2.3\} & 2157.0(1.6) \\ & 2148.0\{-3.3\} & \\ \left(\mathrm{C}_{6} \mathrm{H}_{5}\right)_{3} \mathrm{P}(\mathrm{an}) & 2147.9 \mathrm{sh}(1.7) & \\ & 2149.6(2.2) & \\ \left(\mathrm{C}_{6} \mathrm{H}_{5}\right)_{3} \mathrm{P}(\mathrm{s})^{\mathrm{a}} & 2152.6(1.7) & \\ \left(\mathrm{C}_{4} \mathrm{H}_{9}\right)_{4} \mathrm{P}^{+}(\mathrm{an}) & 2145.4\{-2.5\} & 2158.7(1.5)\end{array}$

Elemental phosphorus (external reference)

$\begin{array}{ll}\text { Pn, red phosphorus (s) } & 2147.15(1.0) \\ & 2153.0 \mathrm{sh}(1.0) \\ & 2155.10(1.2)\end{array}$

${ }^{\mathrm{a}}$ Ref. 6. ${ }^{\mathrm{b}}$ Ref. 7. 


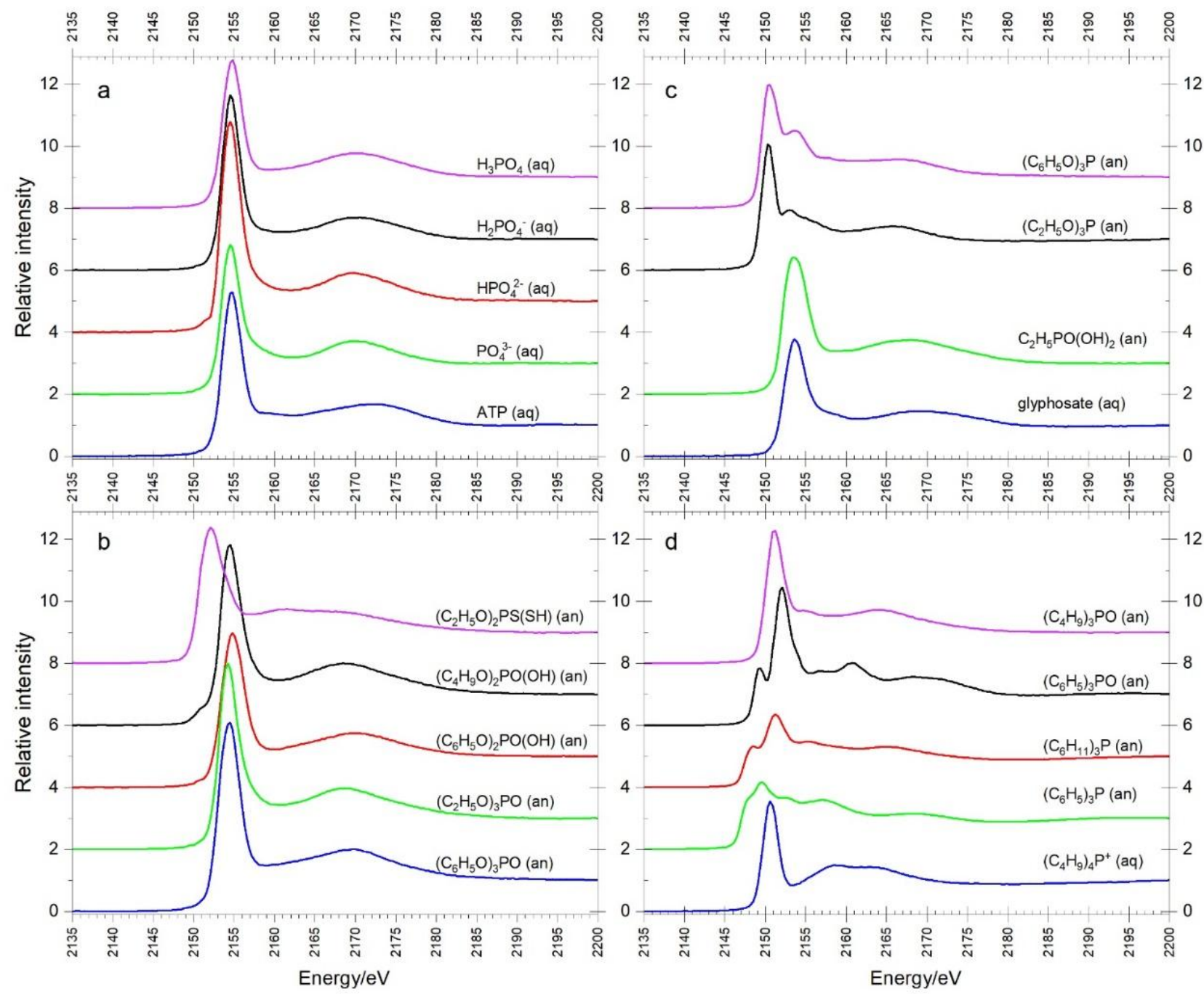

Figure 1. P K-edge XANES spectra of $0.1 \mathrm{~mol} \cdot \mathrm{dm}^{-3}$ aqueous (aq) or acetonitrile (an) solutions of a) adenosine triphosphate (ATP $(\mathrm{aq})$; blue, no offset), sodium phosphate $\left(\mathrm{PO}_{4}{ }^{3-}(\mathrm{aq})\right.$; green, offset $=2)$, sodium hydrogenphosphate $\left(\mathrm{HPO}_{4}{ }^{2-}(\mathrm{aq})\right.$; red, offset $\left.=4\right)$, sodium dihydrogenphosphate $\left(\mathrm{H}_{2} \mathrm{PO}_{4}{ }^{-} \cdot(\mathrm{aq})\right.$; black, offset $\left.=6\right)$, phosphoric acid $\left(\mathrm{H}_{3} \mathrm{PO}_{4}(\mathrm{aq})\right.$; purple, offset $\left.=8\right)$; b) $\mathrm{N}$ (phosphonomethyl)glycine, (glyphosate (aq), blue, no offset), ethylphosphonic acid $\left(\mathrm{C}_{2} \mathrm{H}_{5} \mathrm{PO}(\mathrm{OH})_{2}(\mathrm{an})\right.$; green, offset $\left.=2\right)$, triethylphosphite $\left(\left(\mathrm{C}_{2} \mathrm{H}_{5} \mathrm{O}\right)_{3} \mathrm{P}(\mathrm{an})\right.$, black, offset $\left.=6\right)$, triphenylphosphite $\left(\left(\mathrm{C}_{6} \mathrm{H}_{5} \mathrm{O}\right)_{3} \mathrm{P}(\right.$ an $)$, purple, offset $\left.=8\right)$; c) triphenylphosphate $\left(\left(\mathrm{C}_{6} \mathrm{H}_{5} \mathrm{O}\right)_{3} \mathrm{PO}\right.$ (an), blue, no offset), triethylphosphate $\left(\left(\mathrm{C}_{2} \mathrm{H}_{5} \mathrm{O}\right)_{3} \mathrm{PO}(\mathrm{an})\right.$, green, offset $\left.=2\right)$, diphenylphosphate $\left(\left(\mathrm{C}_{6} \mathrm{H}_{5} \mathrm{O}\right)_{2} \mathrm{PO}(\mathrm{OH})(\right.$ an $)$, red, offset $\left.=4\right)$, di- $n$-butylphosphate $\left(\left(n-\mathrm{C}_{4} \mathrm{H}_{9} \mathrm{O}\right)_{2} \mathrm{PO}(\mathrm{OH})(\right.$ an $)$, black, offset = 6), $O, O$-diethyldithiophosphate $\left(\left(\mathrm{C}_{2} \mathrm{H}_{5} \mathrm{O}\right)_{2} \mathrm{PS}(\mathrm{SH})(\right.$ an), purple, offset $=8)$; d) tetra- $n$ butylphosphonium bromide, $\left(\left(\mathrm{C}_{4} \mathrm{H}_{9}\right)_{4} \mathrm{P}^{+}(\mathrm{an})\right.$, blue, no offset), triphenylphosphine $\left(\left(\mathrm{C}_{6} \mathrm{H}_{5}\right)_{3} \mathrm{P}\right.$ (an), green, offset $=2)$, tricyclohexylphosphine $\left(\left(\mathrm{C}_{6} \mathrm{H}_{11}\right)_{3} \mathrm{P}(\mathrm{an})\right.$, red, offset $\left.=4\right)$, triphenylphosphine oxide $\left(\left(\mathrm{C}_{6} \mathrm{H}_{5}\right)_{3} \mathrm{PO}(\mathrm{an})\right.$, black, offset $\left.=6\right)$, tri- $n$-butylphosphine oxide $\left(\left(n-\mathrm{C}_{4} \mathrm{H}_{9}\right)_{3} \mathrm{PO}(\mathrm{an})\right.$, purple, offset $=8)$.

Ethylphosphonic acid and $N$-(phosphonomethyl)glycine (glyphosate) have their white linepeak ca. $1.0 \mathrm{eV}$ lower than the phosphates, Figure 1c and Table 1. On other hand, the XANES spectra of triphenyl- and triethylphosphite have two well-defined absorption bands at 2150.5 and $2153.6 \mathrm{eV}$, and 2149.4 and $2152.0 \mathrm{eV}$, respectively, Figure 1c. The reason for the presence of two strong bands is the lower symmetry around the phosphorus atom with three 
P-O bonds and a lone electron-pair. Tri- $n$-butyl- and triphenylphosphine oxide have significantly different P K-edge XANES spectra with white lines at 2152.0 and $2151.1 \mathrm{eV}$, respectively, Figure 1d and Table 1. Triphenylphosphine oxide has also a relative intense prepeak at $2149.3 \mathrm{eV}$. Tricyclohexyl- and triphenyl- phosphine are three-coordinate with three $\mathrm{P}$ $\mathrm{C}$ bonds and a lone electron-pair and two significant transitions are observed on the absorption edge. Conversely, as the tetra- $n$-butylphosphonium ion is four-coordinate with a symmetric tetrahedral configuration around phosphorus, it has only one strong white line, at $2150.6 \mathrm{eV}$, Figure 1d.

Solid red phosphorus, used as energy calibration compound, display several transitions in the edge region with the strongest ones at $2147.15,2153.0$ and $2155.1 \mathrm{eV}$ in the absorption edge region. The previously reported data on pure triorganophosphinechalcogenides [4-7] are in good agreement with data reported in this study, Table 1, even though those data were collected as pure compounds. The approximately shift of $-2.5 \mathrm{eV}$ in peak position between the data in this study and those previously reported are attributed to the different fixed reference energies for the two calibration substances used, tetrasodium pyrophosphate $\left(\mathrm{Na}_{4} \mathrm{P}_{2} \mathrm{O}_{7}\right)$ and red phosphorus $\left(\mathrm{P}_{n}\right)$, respectively [6].

The energy range for absorption of sulfur compounds is wide, ca. $13 \mathrm{eV}$ between sulfur compounds in oxidation states -II to +VI, and the XANES characteristics for different kind of sulfur compounds are easy to distinguish from each other [1,2]. Furthermore, the absorption energy of the sulfur compounds increases in the order of the oxidation state. This makes it possible to both qualitatively and quantitatively analyze sulfur compound mixtures with S Kedge XANES spectroscopy. Conversely, the studied phosphorus compounds display a very different pattern with an absorption energy range of only ca. $8 \mathrm{eV}$ including elemental red phosphorus, Figure 1 and Table 1. In order to understand the different behavior of sulfur and phosphorus compounds, and especially the more narrow absorption energy range observed for phosphorus compounds, it is necessary to look at these elements from a different perspective than their formal oxidation number. The Allen electronegativity scale, where phosphorus is assigned a value of 2.253, hydrogen 2.300 (fixed reference value), carbon 2.544, sulfur 2.589, and oxygen 3.610 Pauling units, respectively [15-17], shows that carbon attracts electrons more efficiently than phosphorus, while the opposite is found for sulfur albeit ever so slightly. This means that in a P-C bond, phosphorus will get electron deficit and carbon electron excess, and it is not correct to apply a negative oxidation number on phosphorus in e.g. most organophosphine and phosphonium compounds. Of the compounds used in the present study, elemental red phosphorus feature the lowest oxidation number, zero, and the phosphates the highest, $+\mathrm{V}$, as the difference in Allen electronegativity is large between phosphorus and oxygen. For compounds where phosphorus bind both carbon and oxygen it is much more difficult to apply a correct oxidation number, but it is certainly positive. It shall be pointed out that electronegativity is a property of an atom alone, but it is most likely affected by its surroundings and bonding situation. The position of the absorption edge of such a compound can be a guide to a proper estimation of both the electron density and oxidation number of the absorbing atom, here phosphorus. It can be noted that all phosphorus compounds in this study have absorbance energies higher than that of red phosphorus, $\mathrm{P}_{n}$.

All phosphate compounds display very similar XANES spectra with a strong white line at $2154.5 \pm 0.5 \mathrm{eV}$, but there is no systematic trends in the white-line intensity, Figure $1 \mathrm{a} \& 1 \mathrm{~b}$ and Table 1. This makes it impossible to use P K-edge XANES spectroscopy as a tool to distinguish and analyze unknown phosphate compounds in a solution sample. In solid samples, back-scattering to surrounding metal ions may introduce additional specific features 
in the P K-edge XANES spectra. Other phosphorus compounds are easier to distinguish from each other, but the systematic pattern with increasing absorption energy with increasing oxidation state observed for the sulfur compounds is not applicable for phosphorus compounds with P-C bond and/or a lone electron-pair as carbon has a higher Allen electronegativity than phosphorus, vide supra.

\section{Acknowledgments}

The financial support from the Swedish Research Council is gratefully acknowledged. This work was performed at beam-line 8 at the Synchrotron Light Research Institute (SLRI), Nakhon Ratchasima, Thailand, supported by the Ministry of Science, Technology and Environment of Thailand. We thank the staff at beamline 8 for technical support during our beam-times. Furthermore, Dr. Harald Cederlund, SLU is acknowledged for supplying the ATP and glyphosate samples.

\section{Note}

The authors declare no competing financial or personal interests.

\section{References}

[1] G. Almkvist, K. Boye, I. Persson, K-edge XANES analysis of sulfur compounds: an investigation of the relative intensities using internal calibration. J. Synchrotron Rad. 17 (2010) 683-688.

[2] S. Pin, T. Huthwelker, M. A. Brown, F. Vogel, Combined Sulfur K-Edge XANESEXAFS Study of the Effect of Protonation on the Sulfate Tetrahedron in Solids and Solutions. J. Phys Chem. A 117 (2013) 8368-8376.

[3] B. Rupp, B. Biomolecular Crystallography: Principles, Practice, and Application to Structural Biology, Garland Science, Taylor \& Francis Group, 2009.

[4] G. Küper, R. Chauvistré, J. Hormes, F. Frick, M. Jansen, B. Lüer, E. Hartmann. Phosphorus $\mathrm{K}$ shell photoabsorption spectra of the oxides $\mathrm{P}_{4} \mathrm{O}_{6}, \mathrm{P}_{4} \mathrm{O}_{10}, \mathrm{P}\left(\mathrm{C}_{6} \mathrm{H}_{5} \mathrm{O}\right)_{3}$ and $\mathrm{PO}\left(\mathrm{C}_{6} \mathrm{H}_{5} \mathrm{O}\right)_{3}$ Chem. Phys. 165 (1992) 405-414.

[5] A. Redeker, G. Küper, J. Hormes, F. Frick, M. Jansen, M. Mühlhäuser, Investigation of $\mathrm{P}_{4} \mathrm{O}_{6}, \mathrm{P}_{4} \mathrm{O}_{10}$ and $\mathrm{P}_{4} \mathrm{O}_{6} \mathrm{~S}$ by X-Ray Absorption Spectroscopy at the Phosphorus K-Edge. Phosphorus, Sulfur Silicon 76 (1993) 239-242.

[6] C. Engemann, R. Franke, J. Hormes, C. Lauterbach, E. Hartmann, J. Clade, M. Jansen Xray absorption near-edge spectroscopy (XANES) at the phosphorus K-edge of triorganophosphinechalcogenides. Chem. Phys. 243 (1999) 61-75.

[7] A. Pantelouris, J. Hormes, C. Günther, E. Hartmann, F. Frick, M. Jansen Investigations of $\mathrm{P}_{4} \mathrm{O}_{6} \mathrm{~S}_{n}(n=1-4)$ by X-ray Absorption Spectroscopy at the P and S K-edges. J. Am. Chem. Soc. 118 (1996) 6954-6959.

[8] C. Vogel, C. Rivard, V. Wilken, A. Muskolu, C. Adam, Performance of secondary Pfertilizers in pot experiments analyzed by phosphorus X-ray absorption near-edge structure (XANES) spectroscopy. Ambio 47 (suppl. 1) (2018) S62-S72.

[9] R. Franke, J. Hormes, The P K-near edge absorption spectra of phosphates. Phys. B 216 (1995) 85-95. 
[10]C. Rivard, B. Lanson, M. Cotte, Phosphorus speciation and micro-scale spatial distribution in North-American temperate agricultural soils from micro X-ray fluorescence and X-ray absorption near-edge spectroscopy. Plant Soil 401 (2016) 7-22.

[11] C. Giguet-Covex, J. Poulenard, E. Chalmin, F. Arnaud, C. Rivard, J.-P. Jenny, J.-M. Dorioz, XANES spectroscopy as a tool to trace phosphorus transformation during soil genesis and mountain ecosystem development from lake sediments. Geochim. Cosmochim. Acta 118 (2013) 129-147.

[12] a/ W. Klysubun, P. Kidkhunthod, P. Tarawarakarn, P. Sombunchoo, C. Kongmark, S. Limpijumnong, S. Rujirawat, R. Yimnirun, G. Tumcharern, K. Faungnawakij, SUTNANOTEC-SLRI beamline for X-ray absorption spectroscopy. Synchrotron. Rad. 24 (2017) 707-716, b/ W. Klysubun, P. Sombunchoo, W. Deenan, Performance and status of beamline BL8 at SLRI for X-ray absorption spectroscopy. J. Synchrotron. Rad. 19 (2012) 930-936; http://www.slri.or.th/en/bl8-xas.html (downloaded July 10, 2018)

[13] G. Giesecke, H. Pfister, Präzisionsbestimmung der Gitterkonstanten von $A^{\mathrm{III}} B^{\mathrm{v}}$ Verbindungen. Acta Crystallogr. 11 (1958) 369-371.

[14] A. Thompson, D. Attwood, E. Gullikson, M. Howells, K.-J. Kim, K. Kirz, J. Kortright, I. Lindau, Y. Liu, P. Pianetta, A. Robinson, J. Scofield, J. Underwood, G. Williams, H. Winick, X-ray data booklet, Lawrence Berkley National Laboratory, 2009.

[15] L. C. Allen, Electronegativity is the average one-electron energy of the valence-shell electrons in ground-state free atoms. J. Am. Chem. Soc. 111 (1989) 9003-9014.

[16] J. B. Mann, T. L. Meek, L. C. Allen,Configuration Energies of the Main Group Elements. J. Am. Chem. Soc. 122 (2000) 2780-2783.

[17] J. B. Mann, T. L. Meek, E. T. Knight, J. F. Capitani, L. C. Allen, Configuration Energies of the d-Block Elements. J. Am. Chem. Soc. 122 (2000) 5132-5137. 


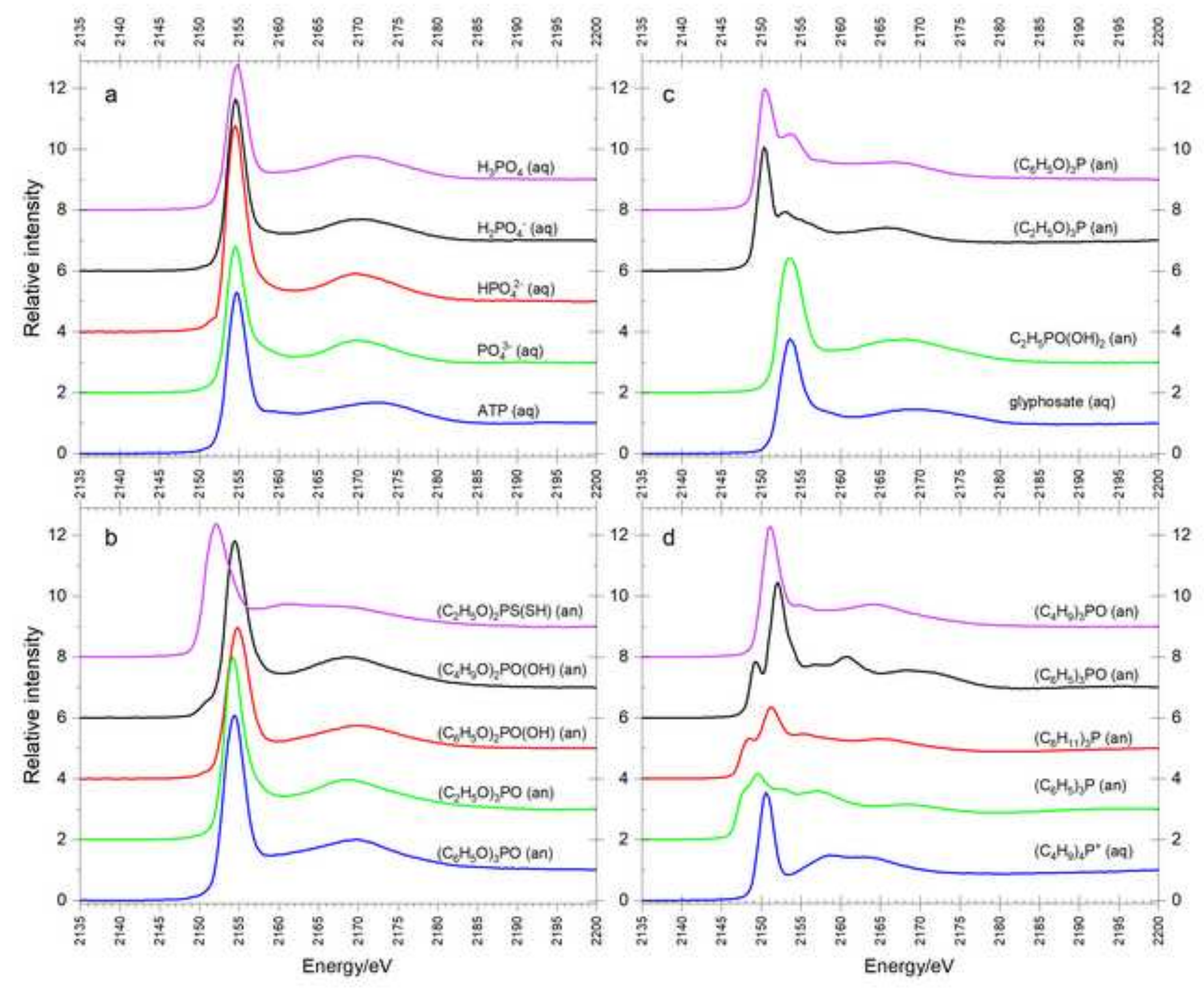

Figure(s)
Click here to download high resolution image 
